\title{
Neumonía organizada criptogenética: a propósito de un caso
}

\author{
Javier Álvarez Granda 1,*, Paloma Lucena Calvet 2, Alejandro Estrada Santiago ${ }^{3}$, Álvaro Conesa \\ Guillén ${ }^{3}$, Ainhoa Gutiérrez García ${ }^{3}$, Emma De Pablo Matesanz ${ }^{3}$, Irene Ruiz Herrero ${ }^{3}$, Ana Roel \\ Conde ${ }^{3}$, Pilar Igea Gracia ${ }^{3}$, Laura Lucía Checa Daimiel ${ }^{3}$, Luisa Jiménez Reyes ${ }^{3}$ y Lidia Romero \\ Calvo $^{3}$ \\ 1 Medicina Interna. Hospital Universitario Central de la Defensa “Gómez Ulla” (Madrid); Facultad de \\ Medicina y Ciencias de la Salud, Universidad de Alcalá; https://orcid.org/0000-0002-6928-4801 \\ 2 Medicina Interna. Hospital Universitario Central de la Defensa “Gómez Ulla” (Madrid); Facultad de \\ Medicina y Ciencias de la Salud, Universidad de Alcalá; https://orcid.org/0000-0003-0692-7010 \\ 3 Medicina Interna. Hospital Universitario Central de la Defensa “Gómez Ulla” (Madrid) \\ * Autor correspondencia: javieralvarezgranda@gmail.com
}

DOI: https://doi.org/10.37536/RIECS.2020.5.1.197

Recibido: 16/03/2020; Aceptado: 21/04/2020; Publicado: 30/05/2020

\section{Introducción y presentación del caso}

Se presenta el caso de una paciente mujer de 43 años de edad que acude a su médico de atención primaria en 2 ocasiones y posteriormente al servicio de urgencias por disnea progresiva hasta hacerse de moderados esfuerzos.

Entre sus antecedentes personales la paciente no presenta reacciones alérgicas medicamentosas conocidas, hábitos tóxicos ni factores de riesgo cardiovascular, diagnosticada en la infancia de tos ferina y de cólicos reno-ureterales de repetición. No refiere intervenciones quirúrgicas. Es independiente para las actividades básicas de la vida diaria, trabaja de dependienta en un supermercado, no contacto con animales ni exposición a tóxicos ambientales. Niega tratamiento en la actualidad.

La paciente acude al servicio de urgencias del Hospital Central de la Defensa "Gómez Ulla" por disnea progresiva hasta hacerse de moderados esfuerzos con empeoramiento de su clase funcional (mMRC I बII), sin aumento de tos seca en comparación a su situación basal ni expectoración blanquecina, de 3 meses de evolución., así como sensación distérmica y fiebre termometrada en su domicilio de $\mathrm{T}^{0} 38.5^{\circ} \mathrm{C}$ en las 2 últimas semanas. La paciente ha sido valorada previamente en 2 ocasiones por su médico de atención primaria 1 semana antes del episodio actual y, ante la sospecha de bronquitis aguda le ha pautado antibioterapia empírica vo con Levofloxacino, con escasa mejoría de su sintomatología clínica. No opresión centrotorácica ni palpitaciones, no aumento de edema en MMII. No alteraciones digestivas ni urinarias. Por otra parte, la paciente refiere pérdida de peso cuantificada de $18 \mathrm{Kg}$ en los últimos 3 años que asocia con dieta especial (abundante ingesta de fruta, verduras y lácteos). No mialgias ni dolor articular.

A su llegada a urgencias la paciente se encuentra normotensa (TA: 127/77 mmHg) con frecuencia

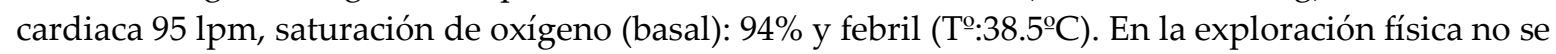
objetiva ingurgitación yugular, bocio ni adenopatías. En la auscultación cardiaca (AC) la paciente se encuentra rítmica sin soplos audibles. En la auscultación pulmonar (AP) presenta murmullo vesicular conservado y destaca la presencia de crepitantes secos bibasales (de predominio en base pulmonar derecha) y en campo medio derecho. Abdomen blando y depresible, no doloroso sin signos de peritonismo ni de defensa abdominal con ruidos hidroaéreos conservados. No edema en MMII. Exploración articular y neurológica sin alteraciones.

Se solicita analítica en la que se objetiva función renal e ionograma sin alteraciones con perfil hepático normal. Sistemático de orina sin alteraciones. En la gasometría arterial (basal) se objetiva hipoxemia (pH 7.43, pCO2 35.2 mmHg, pO2 70.8 mmHg, HCO3 23.3 mEq/L). Elevación de reactantes 
de fase aguda con PCR $5.7 \mathrm{mg} / \mathrm{dl}$ y VSG $117 \mathrm{~mm} / \mathrm{h}$, con leucocitosis (leucocitos 13240 con Neutrófilos 75\%), anemia normocítica-hipocrómica ( $\mathrm{Hb} 11.2 \mathrm{~g} / \mathrm{dl}, \mathrm{VCM} 90$ fl, HCM 29 pg) ferropénica (Hierro 19 $\mathrm{mcg} / \mathrm{dl}$ con IST $17 \%)$.

Se realiza radiografía de tórax (Figura 1) en la que se objetiva patrón intersticial bilateral con condensaciones parenquimatosas bibasales de predominio en base pulmonar derecha (con borramiento de cúpula diafragmática derecha) y posible nódulo con calcificaciones en su interior en lóbulo medio derecho.

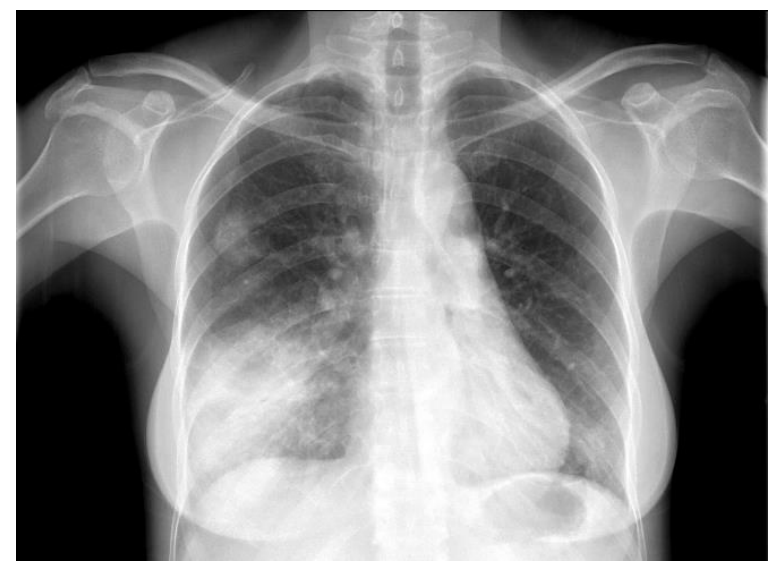

Figura 1 Radiografía de Tórax PA y lateral. Condensación parenquimatosa en lóbulo inferior derecho (LID) con borramiento de hemidiafragma derecho, posible nódulo en lóbulo medio derecho (LMD).

Dados los hallazgos clínicos y radiológicos la paciente ingresa a cargo del servicio de Medicina Interna con juicio clínico inicial de neumonía adquirida en la comunidad (NAC) bilateral. Se inicia antibioterapia empírica con Ceftriaxona y Azitromicina que, tras confirmación de resultados microbiológicos negativos (hemocultivos $\mathrm{x} 2$, urocultivo, cultivo de esputo, antigenuria para Legionella y Pneumococco, Mantoux, BAAR y cultivo de Lowenstein así como serologías virales (VIH, VHA, VHB, VHC, Influenza virus A y B, Parainfluenza Virus I, II y III) así como de ausencia de mejoría clínica ni radiológica (en total la paciente ha recibido 11 días de antibioterapia) es retirada al 6 o día de ingreso. Se abre entonces una ventana terapéutica para valorar si la paciente presenta nuevo episodio febril.

Durante el ingreso se solicita TC de tórax (Figura 2) en la que se objetivan opacidades nodulares parcheadas bilaterales con broncograma aéreo con áreas de vidrio deslustrado bibasales y en lóbulo medio derecho. No adenopatías ni masas sospechosas de malignidad.

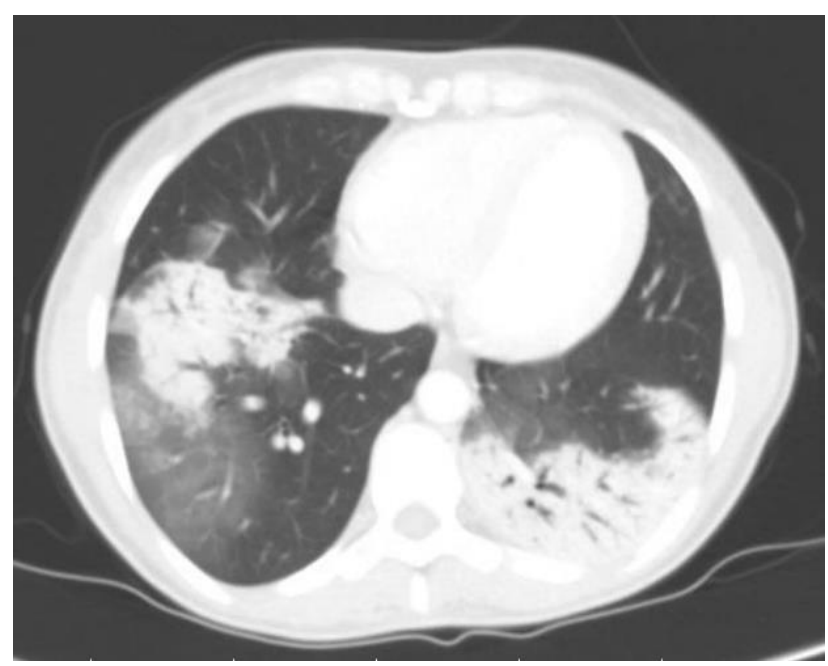

Figura 2 TC Tórax. Opacidades nodulares parcheadas bilaterales con broncograma aéreo con áreas de vidrio deslustrado bibasales y en lóbulo medio derecho. No adenopatías. No masas sospechosas de malignidad. 
En la búsqueda de alternativas etiológicas para este cuadro de disnea de moderados esfuerzos, síndrome febril y pérdida de peso se realiza estudio inmunológico (IgG 1370, IgA 509, IgM 129), y autoinmunidad (ANA, AntiDNA, antiSm, Anti-SSA y anti-SSB, anti-Centrómero, anti-Jo1, antiCCP y Factor Reumatoide) así como marcadores tumorales. Posteriormente tras valoración conjunta con Neumología se realiza una exploración complementaria que permite el diagnóstico.

\section{Diagnóstico diferencial y diagnóstico final}

La paciente presenta un cuadro de disnea progresiva hasta hacerse de moderados esfuerzos y pérdida de peso de 3 meses de evolución, por lo que lo catalogamos de crónico, con patrón intersticial bilateral. En primer lugar, a pesar de que la evolución del cuadro no impresiona es necesario descartar un proceso infeccioso como responsable, dada la elevación de RFA así como el proceso febril que presenta la paciente. Durante el ingreso hospitalario no se objetiva aislamiento microbiológico y la paciente no presenta mejoría clínica a pesar de la antibioterapia empírica pautada, por lo que, tras descartar los principales agentes etiológicos (Staphylococcus aureus, Streptococcus pneumoniae, Mycobacterium tuberculosis, Pseudomonas aeruginosa, Klebsiella pneumoniae, agentes virales...) se decide retirar antibioterapia. En segundo lugar, ante la presencia de un patrón intersticial bilateral es necesario descartar un proceso iatrogénico, en la literatura hay descritos casos secundarios al uso de fármacos como Amiodarona, Penicilamina, Betabloqueantes, Ciclofosfamida, Fenitoína... que podemos descartar dado que la paciente no los ha recibido.

En el diagnóstico diferencial del patrón intersticial bilateral es preciso descartar procesos autoinmunes como etiología responsable, tales como artritis reumatoide (AR), lupus eritematoso sistémico (LES), esclerosis sistémica, dermatomiositis o síndrome de Sjogren, entre otros. Nuestra paciente no cumple criterios clínicos ni analíticos (estudio de autoinmunidad negativo) para ninguna de estas entidades, por lo que nos hace descartar razonablemente esta etiología. Por otra parte, en el estudio radiográfico con TC Body no se objetivan masas sospechosas de malignidad y los marcadores tumorales resultaron negativos, por lo que no impresiona que el cuadro sea secundario a proceso tumoral.

Nos centraremos pues en las neumonías intersticiales idiopáticas (NII), un grupo heterogéneo de entidades en las que se produce una afectación del intersticio pulmonar que puede progresar a distintos grados de fibrosis, y que cursan clínicamente con disnea de moderados esfuerzos, crónica en el 75\% de los casos, así como tos seca, pérdida de peso ( $>10 \mathrm{~kg}$ ) y crepitantes secos en la exploración física. Entre ellas, la más importante dada su elevada prevalencia y mal pronóstico por mala respuesta al tratamiento glucocorticoideo es la Neumonía Intersticial Usual (NIU), por lo que nuestra búsqueda etiológica debe ir dirigida a descartar esta entidad. Para ello, durante el ingreso hospitalario se ha realizado fibrobroncoscopia en la cual no se objetivan hallazgos macroscópicos concluyentes, con un cociente CD4/CD8 $1.1(>1)$ y se toman muestras de biopsia transbronquial, la cual dada su baja sensibilidad (64\%) y valor predictivo negativo (40\%) no constituye el gold standard en las NII. Los resultados de Anatomía Patológica (Figura 3) describen agregados de tejido fibrótico en la luz de los alveolos, con preservación estructural del parénquima pulmonar, lo cual permite establecer el diagnóstico de Neumonía Organizada. 


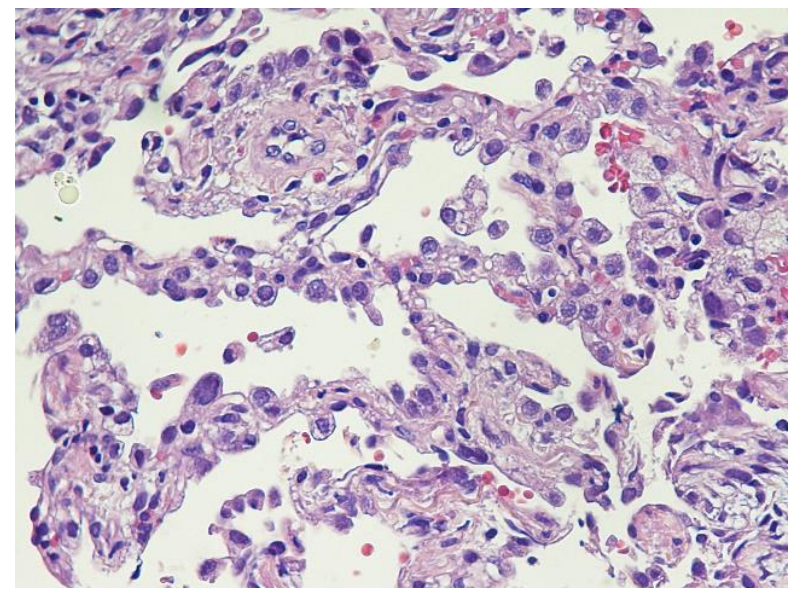

Figura 3 Biopsia transbronquial. Se objetiva la presencia de "cups" o agregados de tejido fibrótico en el interior de la luz de los alveolos (lo cual permite descartar patrón NIU), con preservación de la arquitectura del parénquima pulmonar, datos que sugieren neumonía organizada como responsable del cuadro.

La Neumonía Organizada (NO), anteriormente denominada bronquiolitis obliterante con neumonía organizada (BONO) es la tercera NII en frecuencia. En la mayoría de los casos es idiopática o "Criptogenética" aunque también puede ser secundaria a procesos autoinmunes (AR, LES, esclerosis sistémica...), infecciosos, farmacológicos o inflamatorios. Se produce por una lesión en la membrana basal de los alveolos que produce una distorsión y necrosis de los neumocitos, con pérdida de la integridad endotelial que permite la migración y entrada de los fibroblastos a la luz alveolar, donde se diferencian a miofibroblastos y generan agregados de tejido fibrótico en el interior de los mismos. Estos "cups" o agregados son los responsables de la imagen radiológica de opacidades pulmonares bilaterales de predominio bibasal, subpleural y periférico, de carácter migratorio (ya que pueden pasar de un alveolo a otro a través de los poros de Kohn), con vidrio deslustrado. La clínica es común al resto de NII, la cual presenta nuestra paciente, así como desde el punto de vista analítico (leucocitosis, elevación de PCR y VSG, anemia...) y funcional (patrón restrictivo con disminución de DLCO).

Los resultados anatomo-patológicos, en conjunción con la clínica y las técnicas de imagen compatibles, nos permiten establecer el diagnóstico de Neumonía Organizada Criptogenética (NOC) como responsable del cuadro que presenta nuestra paciente. En los casos leve se puede valorar no tratar (y realizar seguimiento en consultas externas cada 8-12 semanas) o tratar con Macrólidos como Claritromicina durante 6 meses por su efecto antiinflamatorio. En los casos moderados, como el que presenta nuestra paciente, el tratamiento de elección son los glucocorticoides, como la Prednisona a dosis de $0.75-1 \mathrm{mg} / \mathrm{Kg} / 24$ horas vo, con una respuesta completa según la literatura en torno al $60 \%$ y parcial en el $24 \%$ de los casos. En nuestra paciente se pauta inicialmente Prednisona (a dosis $1 \mathrm{mg} / \mathrm{Kg}$ ) $60 \mathrm{mg} / 24$ horas vo, con buena respuesta clínica y resolución del cuadro febril, que se mantiene durante 6 semanas para posteriormente iniciar tappering a dosis de $0.5 \mathrm{mg} / \mathrm{Kg} / 24$ horas vo durante 4 semanas y continuar descenso de $10 \mathrm{mg}$ semanales hasta su retirada definitiva a los 6 meses tras el alta hospitalaria, con resolución radiográfica como se muestra en la figura 4. 


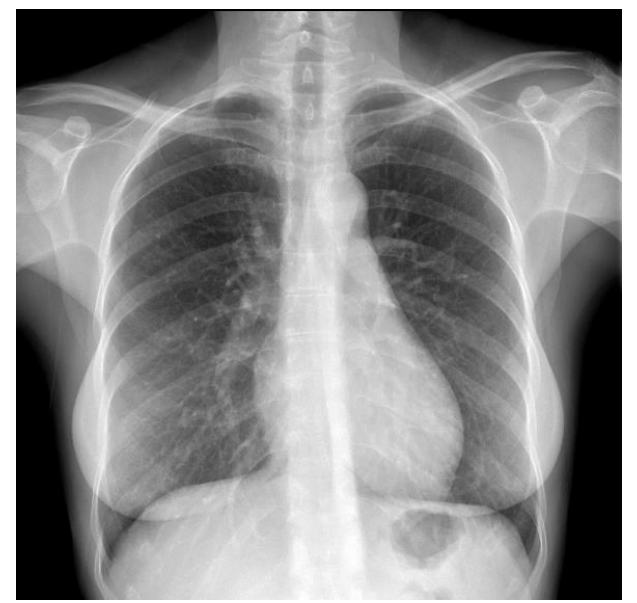

Figura 4 Radiografía de tórax PA. Tras retirada de tratamiento glucocorticoideo (a los 6 meses tras el alta hospitalaria) se objetiva resolución de las opacidades pulmonares bibasales así como en lóbulo medio derecho (LMD), y del vidrio deslustrado

Agradecimientos: Dra. Paloma Lucena Calvet (Medicina Interna), Dra. Wagner Struwing (Neumología), Dr. Francisco Rueda (Anatomía Patológica).

Contribución de los autores: Para artículos de investigación con varios autores, debe proporcionarse un párrafo corto para especificar sus contribuciones individuales. Por ejemplo: "X.X. Y.Y. han concebido y diseñado los experimentos; X.X. realizaron los experimentos; X.X. y Y.Y. analizaron los datos; Y.Y. escribió el artículo". La autoría debe limitarse a aquellos que han contribuido sustancialmente al trabajo.

Conflictos de Intereses: Declarar los conflictos de intereses o si no procede se escribirá: "los autores no declaran conflicto de intereses". Los autores deben identificar y declarar cualquier circunstancia personal o el interés que pueden percibirse como influir indebidamente en la representación o interpretación de resultados de la investigación divulgada. Cualquier papel de los patrocinadores de fondos en el diseño del estudio; en la colección, análisis o interpretación de los datos; en la escritura del manuscrito o en la decisión de publicar los resultados deben declararse en esta sección. Si no hay ningún papel, por favor indicar "los patrocinadores fundadores no tenían ningún papel en el diseño del estudio; en la colección, análisis o interpretación de los datos; en la escritura del manuscrito y en la decisión de publicar los resultados.

\section{Abreviaturas}

Las siguientes abreviaturas son usadas en este manuscrito:

RFA: Reactantes de Fase Aguda

NII: Neumonía Intersticial Idiopática

NIU: Neumonía Intersticial Usual

NOC: Neumonía Organizada Criptogenética

AR: Artritis Reumatoide

LES: Lupus Eritematoso Sistémico 


\section{Bibliografía consultada}

1. Cryptogenic organizing pneumonia: A report of 25 cases and review of the literatura. Medicine 1995, Jul; 74(4):201-211.

2. Bronchiolitis obliterans organizing pneumonia, clinical and roentgenological features in 26 cases. F.Serna et al. Respiration 2005; 72:254-262.

3. Interstitial lung disease guideline: the British Thoracic Society in collaboration with the Thoracic Society of Australia and New Zealand and the Irish Thoracic Society. A. U. Wells et al. 2012.

(C) 2020 por los autores; Esta obra está sujeta a la licencia de Reconocimiento 4.0

Internacional de Creative Commons. Para ver una copia de esta licencia, visite http://creativecommons.org/licenses/by-nc-nd/4.0/. 